\title{
Cancer mortality among magazine printing workers
}

Danièle Luce, Marie-France Landre, Thierry Clavel, Isabelle Limousin, Sylvie Dimerman, Jean-Jacques Moulin

\begin{abstract}
Objectives-After an inquiry from the employees of an offset printing plant, a historical cohort study was conducted to investigate cancer mortality among these workers.

Methods-The cohort comprised 262 men, who contributed 2771 person-years of observation. 16 deaths were identified during the follow up period (1980-91). Expected numbers of deaths were derived from age specific regional rates. Standardised mortality ratios (SMR) and 95\% confidence intervals (95\% CIs) were calculated.

Results-An increased cancer mortality was found after 10 years of employment (SMR 213, 95\% CI 98 to 405, based on nine deaths), mainly due to a high mortality from lung cancer (SMR 381, 95\% CI 104 to 975, four deaths), and from oesophageal cancer (SMR 1049, 95\% CI 216 to 3065, three deaths). For workers with at least 20 years since the start of employment, the SMR was 262 (95\% CI 105 to 540) for all cancer sites, 447 (95\% CI 92 to 1306) for lung cancer, and 1094 (95\% CI 132 to 3952) for oesophageal cancer. The increased cancer mortality was concentrated among pressmen.
\end{abstract}

Conclusion-Although based on small numbers, the findings suggest an increased risk of cancer among these workers, which should be further investigated.

(Occup Environ Med 1997;54:264-267)

Keywords: printing workers; cancer

Several investigators have reported an increased cancer mortality among workers in the printing industry. Studies have been conducted among various groups of printing workers, and excess risks have been found for different cancer sites, particularly for lung cancer, ${ }^{1-6}$ haematopoietic neoplasms, ${ }^{578}$ and colorectal cancer. ${ }^{3}$ 7-9 Increased risks have also been detected for melanoma, ${ }^{10}{ }^{11}$ cancers of the buccal cavity and pharynx, ${ }^{39}$ pancreas, ${ }^{37}$ kidney, ${ }^{56}$ and liver. ${ }^{67}$ However, the mortality experience of workers in offset printing has not been specifically studied.

In 1991, employees in an offset printing plant expressed concern about a high number of cancer deaths. We thus initiated a mortality cohort study, to find whether cancer mortality was increased among these workers relative to the general population and to examine mortality patterns which could suggest an occupational aetiology.

\section{Material and methods}

The plant has produced weekly and monthly magazines, and the four colour offset printing process has been used since the start of printing in 1956. Printing was carried out until 1972 with sheet fed offset printing machines, then with web fed offset litho presses. Ink mists may be generated when the presses are running. Printing inks may contain polycyclic aromatic hydrocarbons, including benzo(a)pyrene, and other known or suspected carcinogens, such as dichlorobenzidine derived dyes. In the plant, the offset litho machines included a damping system, which used an isopropanol solution. The presses were cleaned after each operating cycle, and various solvents (mainly petroleum solvents) were used during cleaning operations.

Reliable personnel records were available only since 1980 . The study population was then defined as all male workers still employed on 1 January 1980 (211 men) or employed since then ( $51 \mathrm{men})$. The cohort included only workers who had been employed for at least one year. For each worker, the contribution to person-years at risk started after they had been employed for one year or at the beginning of the follow up period (1 January 1980), whichever occurred later, and was ended on the date of death or at the end of study (31 December 1991).

Vital status was ascertained up to 31 December 1991 from information provided by the registry office of the subject's birthplace, and by the national file of the French National Institute for Statistics (INSEE). Both sources were used for French citizens. As deaths of foreigners are also recorded in INSEE files, if they died in France, foreign workers who had left work and who were not identified as dead were assumed to be alive at the end of follow up. Date and place of birth, date of start and end of employment, and job title were collected for each subject from company's records. For most workers, only the last job title was recorded. However, workers' job mobility has been limited over time, and changes, if any, were usually from an unskilled to a skilled job within the same category. It was therefore possible to categorise each worker according to the following groups: pressmen, packers and forwarders, binders, 
Table 1 Observed deaths and SMRs for selected causes

\begin{tabular}{llll}
\hline Causes of death (ICD-9) & Obs & Exp & $S M R$ (95\% CI) \\
\hline All causes (000-999) & 16 & $14 \cdot 48$ & $110(63$ to 178$)$ \\
All cancer sites (140-239) & 10 & $5 \cdot 37$ & $186(89$ to 342$)$ \\
Oesophagus (150) & 3 & $0 \cdot 36$ & $843(174$ to 2463$)$ \\
Lung (162) & 4 & $1 \cdot 31$ & $305(83$ to 781$)$ \\
Cirrhosis of the liver (571) & 3 & 0.83 & $360(74$ to 1052$)$ \\
\hline
\end{tabular}

maintenance workers, platemakers, and others (mainly administrative workers). Data on smoking were abstracted from the occupational physician's medical records. Causes of death were obtained from the national file of the French National Institute of Health and Medical Research (INSERM), which is responsible for the coding of all French death certificates. Expected numbers of deaths were calculated from regional rates, with 10 year age group specific rates. The reference rates of 1985 were applied to the whole study period. Analyses with national rates and two calendar periods (1980-6, 1987-91) produced similar results and are not presented in this report. Comparisons of observed and expected numbers of deaths were expressed as standardised mortality ratios (SMRs) and exact $95 \%$ confidence intervals (95\% CIs) based on the Poisson distribution were calculated. ${ }^{12}$ The SMRs were also computed according to years since first employment, employment duration, year of hire, age at hire, and job category.

\section{Results}

The cohort comprised 262 men, who contributed 2771 person-years of observation. At the end of the follow up, 228 men were known to be alive, 16 had died, and 18 men who were not identified as dead were assumed to be alive. Table 1 shows the mortality for selected causes. Although slightly increased, all cause mortality was not significantly above that expected. An increased mortality from cancer was found, which was mainly due to an excess of deaths from lung cancer and oesophageal cancer. The other cancer deaths were one from kidney cancer ( $v 0.10$ expected), one from colon cancer ( $v 0.22$ expected), and one from cancer of an unknown site. Also, a high SMR was found for cirrhosis of the liver.
Table 2 shows the distribution of cancer deaths by job category, year of hire, age at hire, duration of employment, and time since first employment. Cancer mortality was significantly increased among pressmen, with high SMRs for lung cancer and oesophageal cancer. No significant excess for any cause of death was found in the other job categories. Significant excesses for all cancer sites, lung cancer, and oesophageal cancer were also found for workers hired before 1970. Among workers hired at ages younger than 30 years, SMRs significantly above 100 were found for lung cancer and oesophageal cancer.

The SMRs increased with interval since first employment and total number of years worked. Only one cancer death (a kidney cancer) occurred among workers with a duration of employment less than 10 years. The SMRs for lung cancer and oesophageal cancer were significantly increased after 10 years or more of employment. For workers after at least 20 years since first employment, there was a significant increase of total cancer mortality and for mortality from oesophageal cancer; a nonsignificant fourfold excess was found for lung cancer. The small numbers did not permit a more detailed analysis.

No consistent pattern was noted when similar analyses were performed for all cause mortality and for cirrhosis of the liver.

\section{Discussion}

Standardised mortality ratios based on small numbers are subject to wide fluctuations, and should be regarded with caution. Nevertheless, several findings suggest that this cohort presents an increased cancer mortality, particularly for lung cancer, which could be related to occupation. The largest SMRs were found among workers with the longest duration of employment and time since first employment, younger age at hire, and the excess was limited to pressmen. No increased cancer mortality was found among workers who began employment after 1970. This may reflect changes in work exposures. However, a sufficient latent period may not yet have passed to show an excess of cancer in this group.

Table 2 Cancer mortality by job category, year of hire, age at hire, duration of employment, and time since first employment

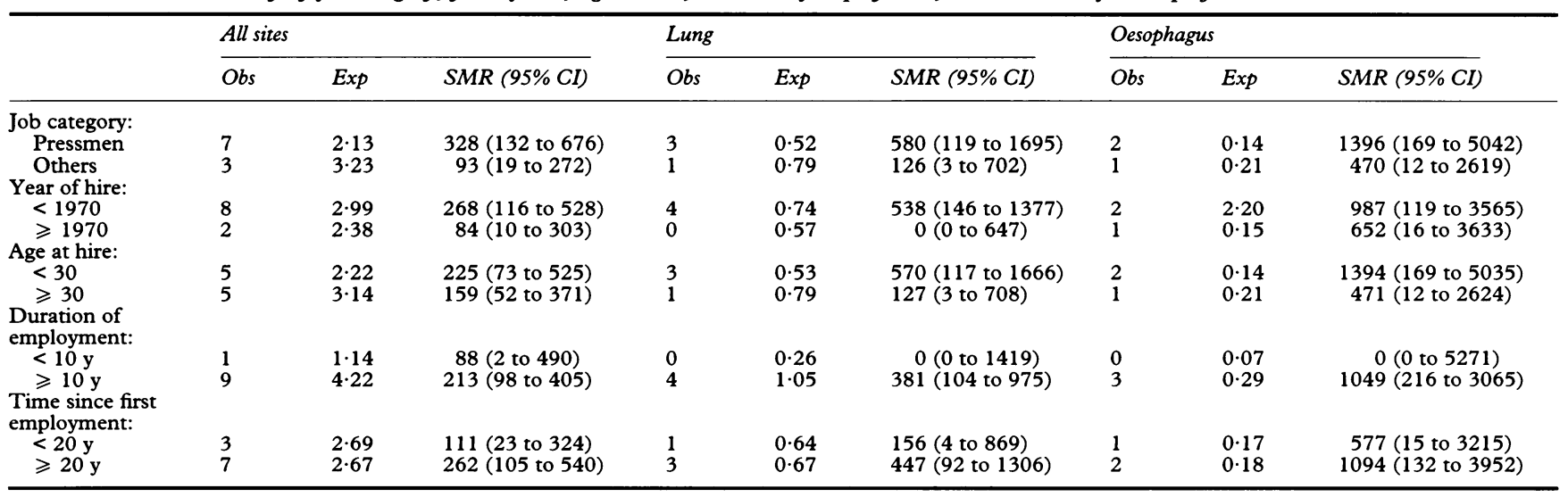


Tobacco smoking is a potential confounder for lung cancer. Smoking habits were available for only $\mathbf{7 5 \%}$ of the workers. It was nevertheless possible to assess the potential confounding effect of smoking on lung cancer by performing the indirect adjustment proposed by Axelson. ${ }^{13}$ Among workers with known smoking habits, $20 \%$ had never smoked, $15.3 \%$ were former smokers, $25.9 \%$ were moderate smokers ( $<20$ cigarettes a day), and $38.8 \%$ were heavy smokers (20 cigarettes a day). The proportions of the various categories of smokers in the French male population in $1980-1,{ }^{14}$ adjusted for age distribution of the cohort, were $25 \%$ never smokers, $26.4 \%$ former smokers, $21.6 \%$ moderate smokers, and $26 \cdot 3 \%$ heavy smokers. Assuming relative risks of $1,5,10$, and 20 among never, former, moderate and heavy smokers respectively, differences between the smoking habits of the cohort and those of the French population would lead to an SMR of 126 for lung cancer. When data on smoking in France in 1991-2 were used for reference, ${ }^{15}$ the lung cancer SMR due to smoking alone would be 139 . Given the magnitude of the SMRs found in this study, it seems that the increase in risk of lung cancer could not be entirely explained by confounding with smoking.

The risk of lung cancer among workers in the printing industry has been investigated in several studies. These studies are difficult to compare because they involved different occupational groups, different sections of the industry, and different printing processes. Increased lung cancer risks were found among workers classified as pressmen, ${ }^{16}$ printers, ${ }^{17}$ typographers, and lithographers. ${ }^{2}$ Significant ${ }^{1}$ or non-significant ${ }^{35}$ excess mortality from lung cancer has been reported among newspaper pressmen. Proportionate mortality studies within other sections of the printing industry failed to show a significant increase in risk, ${ }^{8}$ although slightly increased proportional mortality rates were found. ${ }^{37}$ Only a few studies have provided information on the printing process. A significant increase in risk of lung cancer was found among newspaper pressmen operating rotary letterpress machines in Manchester. $^{1}$ In a recent study from Denmark, ${ }^{6}$ factory workers in newspaper and magazine production showed an excess risk of lung cancer, which was attributed to work with rotary letterpress printing.

Exposure to ink mists, and more specifically to polycyclic aromatic hydrocarbons such as benzo(a)pyrene, was suggested to be a possible cause for the excess in lung cancer among letterpress printers. ${ }^{1}$ Our results indicate that pressmen in magazine production with offset technology may also have had an increased occupational risk of lung cancer. These workers were also exposed to ink mists which contain benzo(a)pyrene. However, the concentration of benzo(a)pyrene in offset inks is lower than in letterpress inks, and offset inks are less liable to produce ink mist. In a recent analysis of offset inks used in France in printing plants similar to the present one, concentrations of benzo(a)pyrene were generally low $(<100$ $(\mu \mathrm{g} / \mathrm{kg})$, although in some inks relatively high concentrations of about $1 \mathrm{mg} / \mathrm{kg}$ were found. The same study found low atmospheric concentrations of benzo(a)pyrene $(<1 \mathrm{~g})$ $1000 \mathrm{~m}^{3}$ ), equivalent to those usually found in urban areas (M Lafontaine, personal communication). On the other hand, although no objective data were available, it is generally admitted that the concentration of polycyclic aromatic hydrocarbons in offset inks has decreased over the past 20 years. Furthermore many tasks which are now automated were performed in the past in the vicinity of unenclosed presses without exhaust ventilation. Consequently, relatively higher exposures may have occurred in the past. Thus the role of ink mist in the excess of lung cancer found in the present study may not be ruled out.

The increase in deaths from oesophageal cancer is more likely to be related to nonoccupational factors. Alcohol consumption is a known risk factor for this disease, and the increased SMR found for cirrhosis of the liver indicated a high proportion of heavy drinkers among these workers. However, mortality from cirrhosis of the liver and from oesophageal cancer did not show similar patterns, so that factors other than smoking and alcohol could not be excluded. Several studies have provided data on the risk of oesophageal cancer among printing workers, ${ }^{35-9}$ none of which have shown a significantly increased risk. Conversely, it is interesting to note that an excess of cirrhosis of the liver has been previously reported in two studies among newspaper pressmen. ${ }^{35}$

Because of the small size of the cohort, the short follow up, and the lack of information on occupational exposures, definitive conclusions could not be reached. Nevertheless, despite its limitations, this study suggests an increased risk of cancer, especially lung cancer, among workers in magazine printing with offset technology. Further investigations of this group of workers, including complete occupational histories and characterisation of specific exposures, are needed to confirm and to clarify the present findings.

We acknowledge the cooperation of the company management and Personnel Department (JP Pegon). We thank Dr JP Raymond for providing data on smoking.

1 Leon DA, Thomas P, Hutchings S. Lung cancer among newspaper printers exposed to ink mist: a study of trade union members in Manchester, England. Occup Environ Med 1994;51:87-94.

2 Malker HSR, Gemne G. A register-epidemiology study on cancer among Swedish printing industry workers. Arch Environ Health 1987;42:73-82.

3 Lloyd JW, Decoufle P, Salvin LG. Unusual mortality experience of printing pressmen. F Occup Med 1977;19: 543-50.

4 Bertazzi PA, Zocchetti C. A mortality study of newspaper printing workers. Am f Ind Med 1980;1:85-97.

5 Paganini-Hill A, Glazer E, Henderson BE, Ross RK Cause-specific mortality among newspaper web pressmen. f Occup Med 1980;22:542-4.

6 Lynge E, Rix BA, Villadsen E, et al. Cancer in printing workers in Denmark. Occup Environ Med 1995;52: 738-44

7 Zoloth SR, Michaels DM, Villalbi JR, Lacher M. Patterns of mortality among commercial pressmen. $\mathcal{F}$ Natl Cancer Inst 1986;76:1047-51

8 Greene MH, Hoover RN, Eck RL, Fraumeni JF. Cancer mortality among printing plant workers. Environ Res 1979;20:66-73

9 Leon DA. Mortality in the British printing industry: a historical cohort study of trade union members in Manchester. Occup Environ Med 1994;51:79-86. 
10 McLaughlin JK, Malker HSR, Blot WJ, Ericsson JLE, Gemne G, Fraumeni JF. Malignant melanoma in the printing industry. Am $\mathcal{F}$ Ind Med 1988;13:301-4.

11 Dubrow R. Malignant melanoma in the printing industry. Am $\mathcal{F}$ Ind Med 1986;10:119-26.

12 Breslow NE, Day NE. Statistical methods in cancer research. Vol 2. The design and analysis of cohort studies. Lyon International Agency for Research on Cancer, 1987.

13 Axelson $\mathrm{O}$. Aspects on confounding in occupational health epidemiology. Scand $¥$ Work Environ Health 1978;4:85-9.

14 Le Laidier S, Morel B. Habitudes de consommation de boissons alcooliques et de tabac et recours aux soins. Solidarité-Santé Etudes Statistiques 1984;1:77-95.

15 Guignon N. Les consommations d'alcool, de tabac et de psychotropes en France en 1991-2. Solidarité Santé 1994; 1:171-85.

16 Menck HR, Henderson BE. Occupational differences in rates of lung cancer. $\mathcal{F}$ Occup Med 1976;18:797-801.

17 Schoenberg JB, Stemhagen A, Mason TJ, Patterson J, Bill

$\mathrm{J}$, Altman R. Occupation and lung cancer risk among

13-21. 
interpretation, the other main topic is epidemiology and those working in health and safety at work.

The meeting will be of particular interest to representatives of authorities responsible for the establishment of occupational exposure limits or the definition of lists of occupational diseases, medical inspectors of workplaces, occupational physicians, safety engineers, representatives of the social groups, the social security institutions, and occupational epidemiologists.

Further information from: the Office for International Relations and Conferences, Adalbert-Stifter-Strasse 65, A-1200 Vienna, Austria. Tel. +43-1-33 111 - 537, Fax +43-1-33 111469 email: presse@auva.or.at

International Symposium on Good Occupational Health Practice and Evaluation of Occupational Health Services. 8-10 June 1998. Hanasaari Cultural Centre, Espoo, Finland

The symposium is organised by the Finnish Institute of Occupational Health (FIOH), the Ministry of Social Affairs and Health, Finland, and the International Commission on Occupational Health (ICOH), Scientific Committee on Health Services Research and Evaluation in Occupational Health.

The aim of this symposium is to stimulate and to promote the international exchange of experiences on achieving good occupational health service practices and to promote development of concepts, strategies, and methodology in evaluating occupational health services (OHS). Topics included in this area are quality and effectiveness, multidisciplinarity, flexibility and good practices with regard to needs of clients and consumers' demands, research on OHS as an advisory service contributing to rational decision making on national, regional, and local levels, as well as on the enterprise level or the OHS service unit level, and the interaction between scientific institutions, service providers, and the health service market. Considering the broad scope of the subject matter of the symposium, issues related to world wide trades and working life are also included.

The programme will include plenary lectures, oral and poster presentations, as well as panel discussions. The working language of the Symposium is English.

Topics include:

- Good occupational health practice, focusing on workplace evaluation and systems evaluation

Keynote lecture: Global trends and developments in occupational health services (objectives and inputs); Jerry Jeyaratnam, ICOH, Singapore

Keynote lecture: Good occupational health practices: Concepts and criteria; Frank van Dijk, The Netherlands

- Evaluation

Keynote dialogue: Strategies and methods for scientific evaluation of occupational health services; Peter Westerholm, Sweden and Kaj Husman, Finland

- Future perspectives

Keynote lecture: Challenges of occupational health services in changing societies and working life; Jorma Rantanen, Finland

- Other topics related to good occupational health practice and occupational health service evaluation
Further information from: Symposium on Good Occupational Health Practice and Evaluation of Occupational Health Services Finnish Institute of Occupational Health Symposium Secretariat, Inkeri Haataja Topeliuksenkatu 41 a A, FIN-00250 Helsinki, Finland; telephone: Int.+358-9-474 7470; fax: Int.+358-9-474 7548; e-mail: Inkeri.Haataja@occuphealth.fi www: http:// www.occuphealth.fi/tiedotus

\section{CORRECTIONS}

Correlation between ${ }^{9} \mathrm{Tc}^{\mathrm{m}}$-HMPAOSPECT brain image and a history of decompression illness or extent of diving experience in commercial divers $T G$ Shields, PM Duff, SA Evans, HG Gemmell, PF Sharp, FW Smith, RT Staff, SE Wilcock (1997;54:247-253).

The bottom row of table 2 should read Total II-V, not I-V. The address for S E Wilcock should be only the Hyperbaric Research Unit, Robert Gordon University, School Hill, Aberdeen AB9 1FR.

Cancer mortality among magazine printing workers Danièle Luce, Marie-France Landre, Thierry Clavel, Isabelle Limousin, Sylvie Dimerman, Jean-Jacques Moulin

(1997;54:264-7)

Page 266 column 2 line 4 should read $<1 \mu \mathrm{g}$, not $<1 \mathrm{~g}$. Also in table 2 for oesophagus $<1970$, the expected number should be 0.20 , not 2.20.

\section{BOOK REVIEWS}

Mechanisms of fibre carcinogenesis: IARC Scientific Publications No 140.

Edited by AB KANE, P BOFFETTA, R SARACCI, JD WILBOUR. (Pp 135; $£ 45)$. 1996. Lyon: IARC. ISBN: 92832-2140-0.

This book represents a collection of reviews written by the participants in a workshop on the mechanisms of fibre carcinogenesis, held at the IARC in Lyon on 9-11 January, 1996. The goals of the workshop were twofold; to review and discuss the current knowledge on the mechanisms of fibre carcinogenesis, and to use this knowledge in the assessment of carcinogenic risks to humans or animals.

The primary outcome of the workshop was the consensus report, which is presented in the first part of the book, and was agreed by all the workshop participants. This report brings to light a surprising number of weaknesses and data gaps in the available literature on fibre characterisation, genotoxicity, cell proliferation or activation, and animal studies. A prime example of such shortcomings is the general lack of information on the characterisation of fibre dose-that is, numbers, dimensions, surface area, chemistry, durability, and biopersistence-for most in vitro and in vivo studies. The report also discusses the relevance of mechanistic data from in vitro and in vivo assays for the evaluation of carcinogenic risk to humans and concludes with several recommended experimental studies which would provide additional data for the future assessment of fibre carcinogenicity.

The remainder of the book focuses on various aspects of mineral fibre carcinogenicity which were outlined in the consensus report, and such reviews express the opinions of their authors. Briefly, the paper by Kane provides a good discussion of the proposed five mechanistic hypotheses for fibre carcinogenesis. Fubini follows up on these hypotheses by examining the interactions between fibres and cells through the analysis of fibre parameters such as crystallinity, micromorphology, elemental analysis, solubility, and adsorption, which are often not considered by most investigators. The report by Jaurand provides cautious consideration to the limitations and feasibility of mutation and cell transformation assays for investigating the mechanistic effects of fibres. Topics presented by Driscoll focus on processes which may contribute to the neoplastic effects of various fibres and current issues such as signal transduction pathways, oxidative stress, antioxidant mechanisms, and protooncogene expression. Donaldson describes in detail the role of reactive oxygen species, cytokines, and growth factors in preneoplastic and fibrotic changes. The advantages and disadvantages of inhalation, intratracheal instillation, and intracavitary injection are reviewed by Oberdörster. The final review, by Davis, discusses the interactions of inhaled particulate matter along with fibres and the potential effects of mixed doses on fibre pathogenicity.

Overall this book is a collection of concise and up to date reviews on the subject of fibre (mainly asbestos) carcinogenesis. It is generally readable, clear, and informative. Its comprehensive tables and references provides a very good introduction for newcomers to the subject, as well as being an excellent resource for examination candidates. Unfortunately, the most appropriate readers (students) will be unable to afford its high price. The sections in the reviews on recommended experimental studies and unanswered questions are worthwhile to the professional audience. These sections state clearly the directions that research should take to close gaps in data and strengthen current information. There are several similar books on the market today which deal with the health effects and actions of mineral dusts; this book will be of interest to those investigators who work predominately with asbestos fibres.

KELLY ANN BÉRUBÉ

Immunopathology of Lung Disease

Edited by RICHARD L KRADIN, BRUCE wS ROBINSON (pp 578; £87.99) 1997. Oxford: Butterworth-Heinemann. ISBN: 0-75069282-0.

This is the first comprehensive text book on the immune responses of the lung in health and disease since Immunology of the Lung and Upper Respiratory Tract, edited by John Bienenstode, was published in 1984. The book 